$\frac{12}{3}, 194850$

UCRLID-116209

\title{
Large Plastic Shells from our Contract with the Lebedev Institute
}

\author{
R. C. Cook
}

February 2, 1994

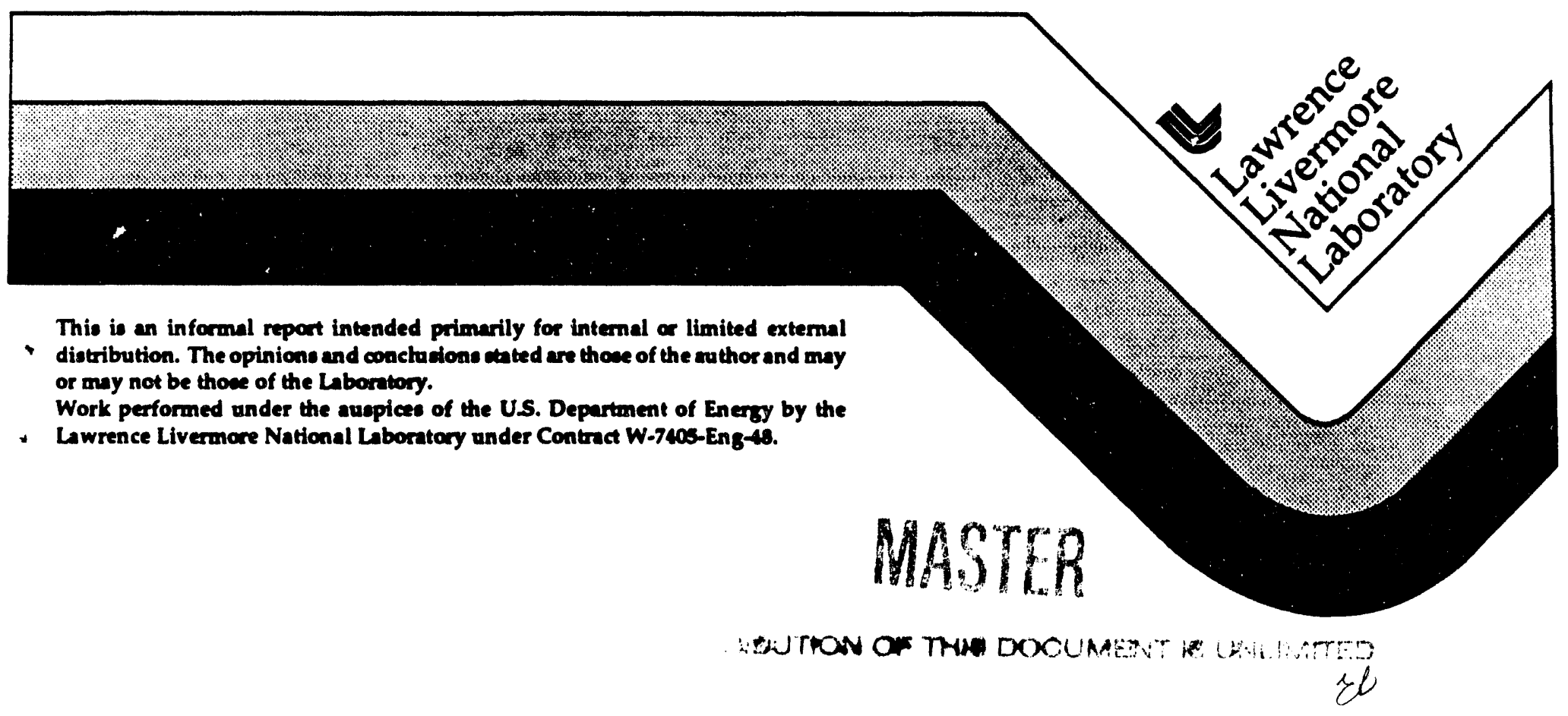




\section{DISCLAIMER}

This document was prepared as an account of work sponsored by an agency of the United States Covernment. Neither the United States Covemment nor the University of California nor any of their employess, makes any warranty, express or imptied, or assumes any legal liability or responsibility for the accuracy, completeness, or usefulness of any information, apparatus, product, or process disclosed, or represents that its use would not infringe privately owned rights. Reference herein to any specific commencial products, processes, or service by trade name, trademark, manufacturer, or otherwise, does not necessarily constitute or imply its endorsement, recommendation, or favoring by the United States Covernment or the University of California. The views and opinions of authors expressed herein do not necesearily state or reflect those of the United States Covernment or the University of California, and shall not be used for advertising or product endorsement purposes.

This report has been reproduced

directly from the beat available copy.

Available to DOE and DOE contractors from the

Office of Scientific and Technical Information

P.O. Box 62, Oak Ridge, TN 37831

Prices available from (615)576-8401, FTS 626-8401

Available to the public from the

National Technical Information Service

U.S. Department of Commerce

5285 Port Royal Rd.,

Springfield, VA 22161 
Date: February 2, 1994 TST 94-013

To: Distribution

From: Bob Cook

Subject: Large Plastic Shells from Our Contract with the Lebedev Institute

Summary

We have a contract with the Department of Neutron Physics at the Lebedev Physical Institute in Moscow to develop the technology to produce plastic shells with diameters of about $2 \mathrm{~mm}$ that would be potentially suitable for NIF targets. They have recently delivered a selection of plastic shells with diameters of about $1 \mathrm{~mm}$. The quality of these shells is in general quite good. The wall thicknesses range from about 4 to $7 \mu \mathrm{m}$. Sphericity looks excellent and wall thickness uniformity may be acceptable. Two shells were sphere-mapped. There are some problems at low modes. In addition there was a great deal of dust and debris from breakage during shipping. However these shells are probably better than any micro encapsulation shells of the same size. Some of the shells will be overcoated for cryogenic liquid layering experiments.

\section{Background}

The target fabrication group at the Lebedev Physical Institute (LPI) in Moscow was a significant contributor to the Soviet ICF Program before the disintegration of the Soviet Union and the emergence of the Independent States. During the visit of several members of this group to LLNL last February we discussed the possibility of supporting work at LPI aimed at producing NIF size capsules. This group had previously demonstrated the capability of producing roughly $1 \mathrm{~mm}$ size plastic capsules, but during the last few years a lack of funds had led to a degradation of capability. As a result of our discussions we set up a development program with a goal of producing $2 \mathrm{~mm}$ diameter plastic shells by the end of two years of work. The support for the first contract year was set at $\$ 24 \mathrm{~K}$. The contract was approved by DOE and commenced in May, 1993. One of the first objectives was to restore their former drop tower capability and to produce $1 \mathrm{~mm}$ diameter shells by the end of the second quarter. Two cassettes of these shells were delivered last November. Due to other priorities they have only recently been characterized.

The LPI group produces shells by dropping polystyrene "frit" through a heated tower in contradistinction to the LLNL approach which uses droplets of a solution of polystyrene in a volatile solvent. The "frit" is basically a partly porous polymer pellet that has been saturated with a "foamer", in this case neopentane. Using this technique they have now produced $1 \mathrm{~mm}$ shells. The LLNL approach produces shells no larger than $0.5 \mathrm{~mm}$ in diameter. The differences may be largely due to heat transfer and the related volatilization of solvent. It should be added that we have not to date made a concerted effort to produce larger shells by solution drop tower methods here at LLNL. 


\section{Shell Characterization}

The shells from one of the two cassettes sent were characterized. It was first noted that there was a fair amount (about 25\%) of breakage during shipping, and that a number of the shells had become dislodged from their positions in the cassette. Partly because of this breakage and resulting debris, the shells were dirty. Clearly we will have to find an improved method for shipping shells from Russia. Optical interferometric analysis of the shells at LLNL gave the outer diameter, average wall thickness, and a " $P_{1}$ ", which would be the offset off the centers of the outer and inner circumference if both were perfectly circular. If this were the case then the $P_{1}$ would be one half of the wall thickness variation from thin to thick. However this interpretation is probably not appropriate since part (perhaps most) of the interferometrically determined $P_{1}$ is due to other factors.

Table I lists the results from the first cassette which originally contained seven rows (A$G)$ of seven shells (1-7) each. Missing numbers (A1-A3, etc.) are shells that were either broken or missing. The shell OD's and wall thicknesses were also measured by LPI and this data is included. Shells in rows A and $G$ had come loose from the cassette during transit and thus correspondence to the LPI measurements is not correct. For rows B through $F$ the diameter agreement is generally to within $10 \mu \mathrm{m}$, and we see at least qualitative wall thickness agreement. LPI also measured wall thickness variation which is expressed as the thickness variation, $\Delta T$, as a fraction of the average wall thickness $T$. There seems to be only a small correlation between the $P_{1}$ and $\Delta T / T$ measurements, suggesting that they measure somewhat different things.

Photos of the interferograms of two of the shells, F3 and F5, are shown in Figure 1. What can be seen in the originals (and hopefully in the reproductions) is a respectable ring pattern and a fair amount of debris on the shells. We have not as yet made any special attempt to clean these shells.

Shells C4 and E5 were sphere-mapped. In Figures 2 and 4 are the actual traces, and in Figures 3 and 5 are displayed the power spectra. The traces show a number of vertical jumps of the AFM tip, probably due to its encounter with debris on the surface. The power spectra show significant power at low modes and a power one to two orders of magnitude higher than what we see on our good $440 \mu \mathrm{m}$ polystyrene shells, the power spectrum of which is sketched on the plots as a dashed line.

LPI indicates that the quality of these shells is not as high as they have produced in the past due to the poor quality of the industrial grade polystyrene starting material they had to work with. They state that they have routinely made shells with a $\Delta T / T$ of less than 0.05 for previous Soviet ICF experiments. We analyzed the polystyrene they used and found it had a $M_{w}$ of $183 \mathrm{~K}$ and a polydispersity $\left(M_{w} / M_{n}\right)$ of about 3.7. The material we use in our solution drop tower process has a $M_{w}$ of about $100 \mathrm{~K}$ and a polydispersity of less than 1.1. It is quite possible that the broad molecular weight distribution in the 
Russian material is responsible for the wall thickness variation they see and perhaps also some of the low frequency surface structure. This will be tested in current LPI experiments with a new and hopefully better grade polymer that they have now or expect to obtain shortly.

\section{Current Plans}

Some of the shells that we have received will be overcoated with a thick $\mathrm{CH}$ plasma polymer layer and used by Jorge Sanchez for cryo liquid layering experiments. Their size matches the current LLE Omega Upgrade target requirements, and thus they will be useful for Sanchez's experiments. Our challenge will be to get them clean enough so that the coatings we put on them are relatively defect free.

It should also be noted that when Omega Upgrade comes on line the first capsule targets will likely be non-cryo $1 \mathrm{~mm}$ plastic shells. It is my evaluation at this time that shells of this size are not being produced at high enough quality by micro-encapsulation techniques to be suitable targets. During the next few months I will be exploring expanded deliveries of what will hopefully be improved capsules from LPI.

Lastly, let me add that these resuits are only milestones on a route that will hopefully lead to $2 \mathrm{~mm}$ diameter capsules that may be suitable for NIF experiments. It is my evaluation that the LPI group has made excellent progress in six months, working with very limited resources in an incredibly turbulent environment. Discussions are now beginning with respect to the level of LLNL support for the second year, to begin late this spring. 
Table I

Russian Plastic Shells from Cassette 1

Measurements in Microns

\begin{tabular}{|c|c|c|c|c|c|c|}
\hline $\begin{array}{l}\text { Shell } \\
\text { Label }\end{array}$ & $\begin{array}{l}\text { Outer } \\
\text { LLNL }\end{array}$ & $\begin{array}{c}\text { ameter } \\
\text { LPI }\end{array}$ & $\begin{array}{c}\text { Wall Th } \\
\text { LLNL. }\end{array}$ & $\begin{array}{c}\text { ness } T \\
\text { LPI }\end{array}$ & $\begin{array}{c}P_{1} \\
\text { LLNL }\end{array}$ & $\begin{array}{l}\Delta T / T \\
L P I\end{array}$ \\
\hline $\mathrm{A} 4$ & 1014 & 1037 & 5.69 & 7 & 1.35 & 0.14 \\
\hline A5 & 1036 & 991 & 5.46 & 5 & 0.56 & 0.18 \\
\hline A6 & 1002 & 1189 & 4.10 & 5 & 1.24 & 0.19 \\
\hline A7 & 1001 & 1189 & 5.23 & 7 & 1.12 & 0.20 \\
\hline B2 & 1038 & 1006 & 7.28 & 6 & 2.80 & 0.19 \\
\hline B3 & 1001 & 1006 & 8.42 & 8 & 1.23 & 0.18 \\
\hline B4 & 1043 & 1037 & 4.55 & 5 & 1.13 & 0.06 \\
\hline B5 & 966 & 976 & 5.92 & 5 & 1.23 & 0.08 \\
\hline B6 & 994 & 1006 & 4.32 & 5 & 1.07 & 0.19 \\
\hline B7 & 1001 & 1006 & 5.01 & 4 & 0.34 & 0.20 \\
\hline $\mathrm{C} 1$ & 1067 & 1067 & 5.23 & 5 & 1.12 & 0.15 \\
\hline C2 & 1010 & 1021 & 4.78 & 5 & 1.13 & 0.20 \\
\hline C4 & 1003 & 1004 & 6.14 & 5 & 1.63 & 0.10 \\
\hline C7 & 965 & 976 & 4.78 & 6 & 1.24 & 0.16 \\
\hline D1 & 935 & 944 & 4.10 & 5 & 0.90 & 0.20 \\
\hline D2 & 1086 & 1098 & 7.74 & 8 & 0.78 & 0.15 \\
\hline D3 & 987 & 991 & 4.55 & 4 & 1.46 & 0.10 \\
\hline D4 & 1177 & 1189 & 8.42 & 10 & 0.50 & 0.25 \\
\hline D5 & 985 & 1006 & 7.74 & 8 & 1.23 & 0.29 \\
\hline D6 & 1131 & 1143 & 5.01 & 4 & 0.56 & 0.06 \\
\hline D7 & 1180 & 1189 & 7.51 & 7 & 1.68 & 0.10 \\
\hline E2 & 1153 & 1143 & 6.14 & 6 & 2.36 & 0.10 \\
\hline E3 & 970 & 976 & 6.37 & 5 & 0.56 & 0.15 \\
\hline $\mathrm{E} 4$ & 1101 & 1098 & 4.10 & 4 & 0.68 & 0.15 \\
\hline E5 & 1165 & 1174 & 4.78 & 4 & 0.23 & 0.20 \\
\hline E6 & 1029 & 1037 & 4.10 & 4 & 1.13 & 0.20 \\
\hline E7 & 1037 & 1037 & 7.05 & 6 & 1.46 & 0.20 \\
\hline F1 & 978 & 991 & 10.92 & 8 & 2.33 & 0.15 \\
\hline F2 & 1046 & 1052 & 5.69 & 7 & 1.57 & 0.15 \\
\hline F3 & 955 & 960 & 6.83 & 4 & 1.57 & 0.10 \\
\hline F5 & 1091 & 1098 & 5.23 & 5 & 0.67 & 0.10 \\
\hline F6 & 990 & 991 & 5.92 & 4 & 0.22 & 0.20 \\
\hline$\overline{\mathrm{G} 3}$ & 1060 & & & - & & \\
\hline $\begin{array}{l}\text { G3 } \\
\text { G5 }\end{array}$ & $\begin{array}{r}1060 \\
961\end{array}$ & 1021 & 4.32 & 4 & 0.68 & 0.15 \\
\hline $\begin{array}{l}\text { G5 } \\
\text { G6 }\end{array}$ & $\begin{array}{l}961 \\
986\end{array}$ & 1037 & 6.83 & 4 & 0.56 & 0.20 \\
\hline G6 & 986 & 1037 & 5.92 & 6 & 0.62 & 0.15 \\
\hline ave & 1034 & 1049 & 5.89 & 5.6 & 1.11 & 0.16 \\
\hline
\end{tabular}




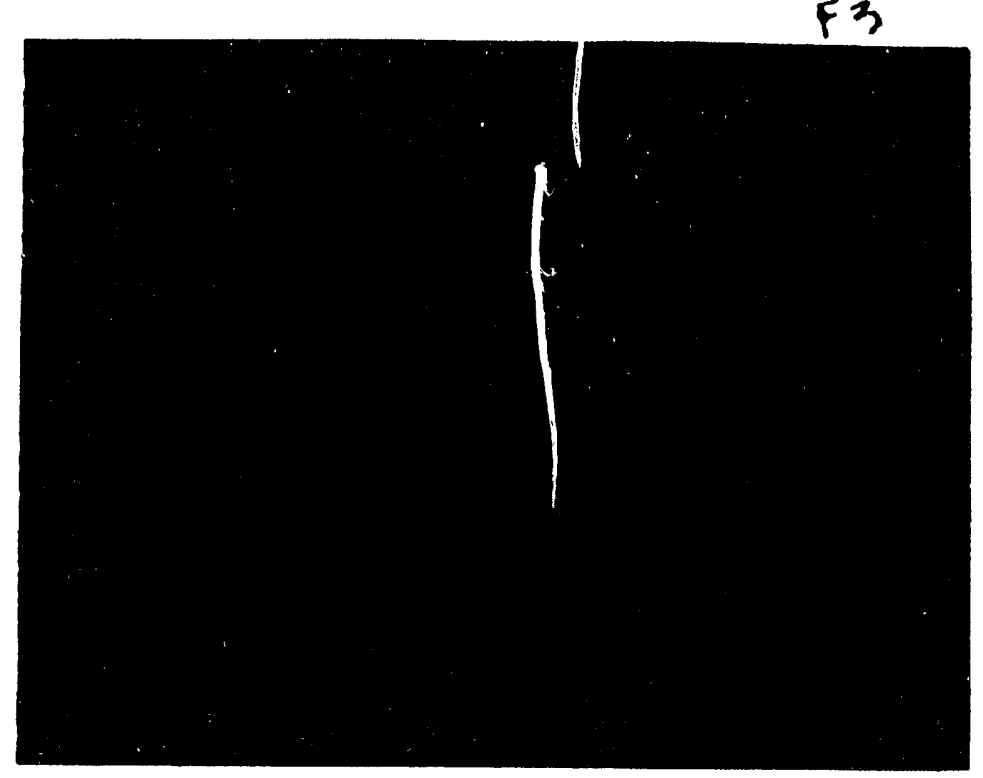

F5

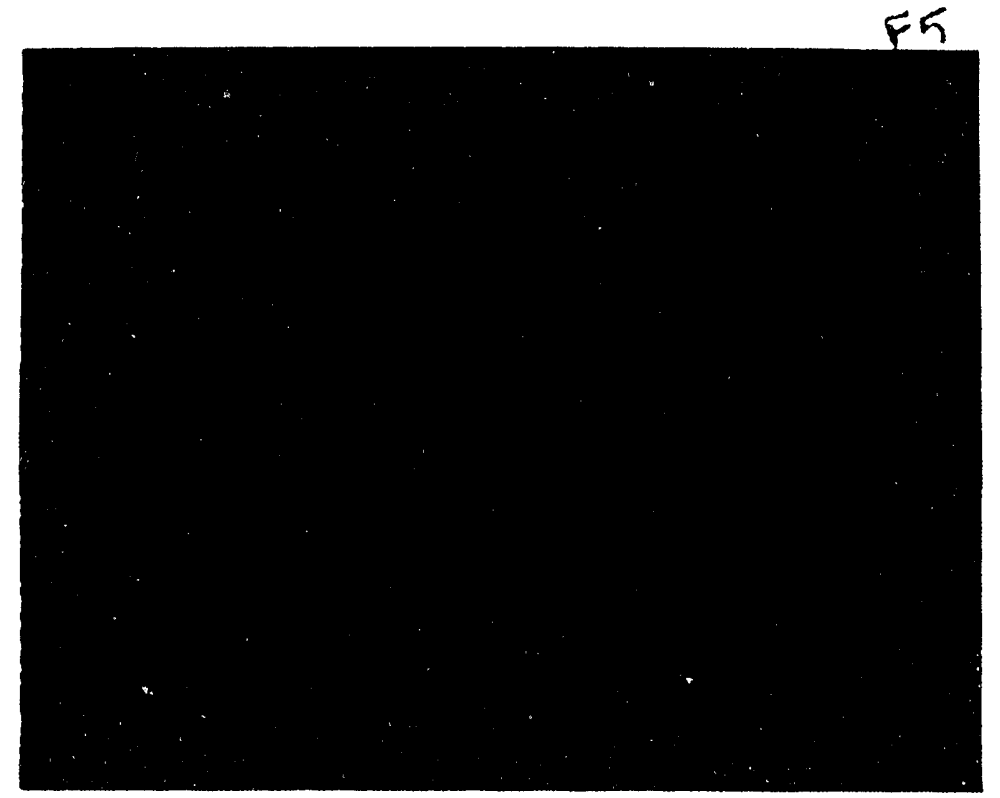

Figure 1. Interferograms of shells F3 and F5. Note dirt present as black specks. 


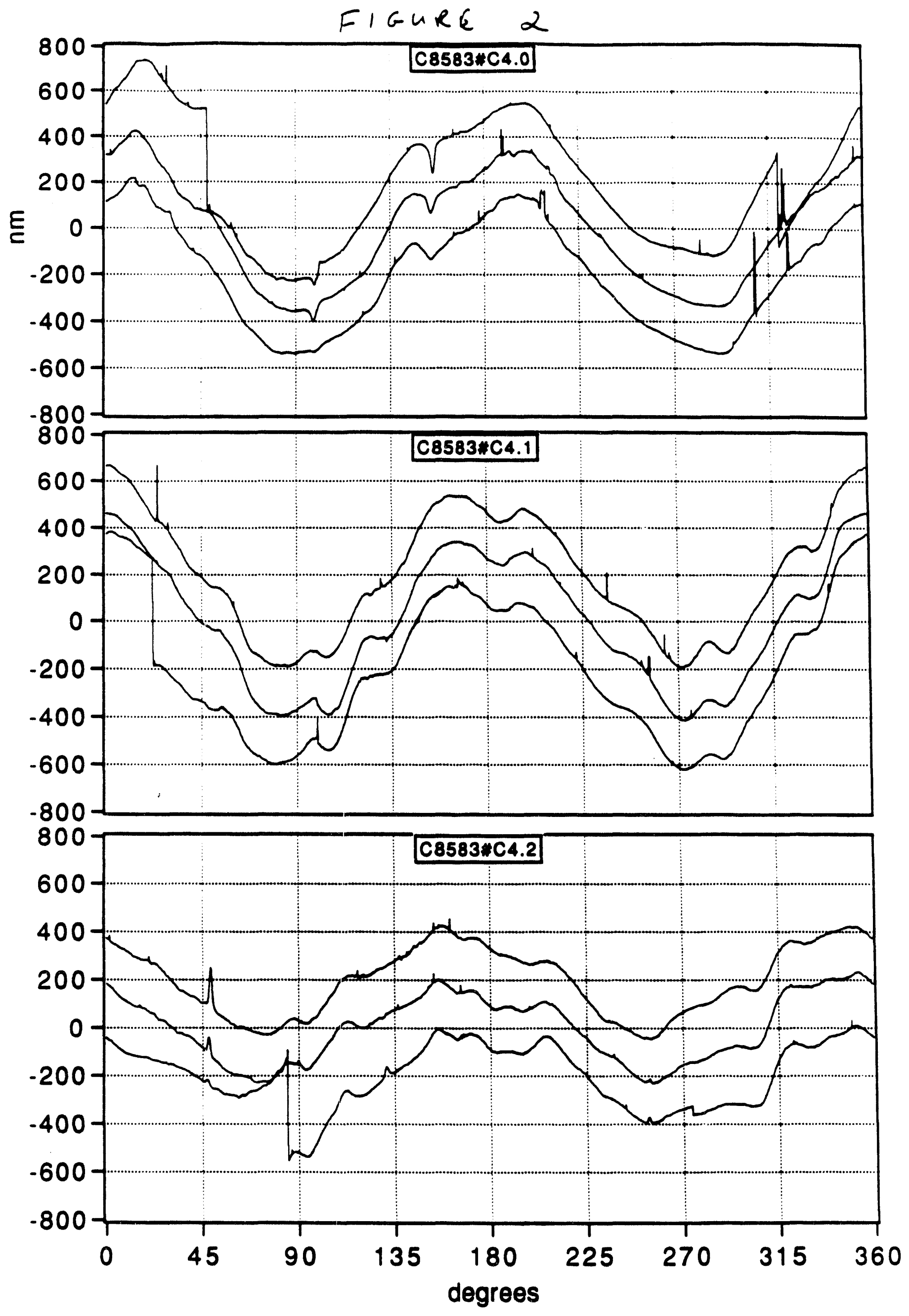




$$
\text { flgurr } 3
$$

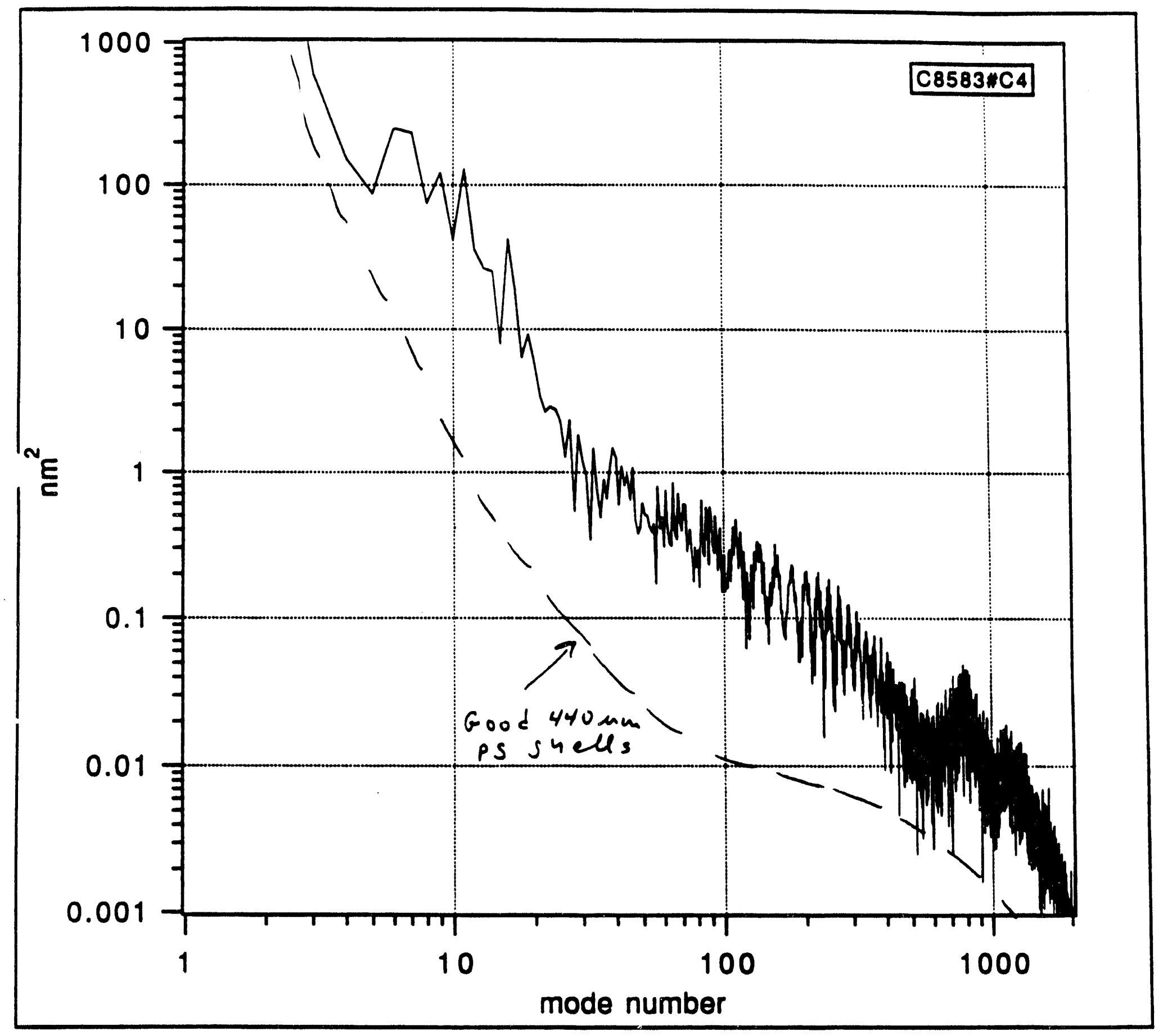




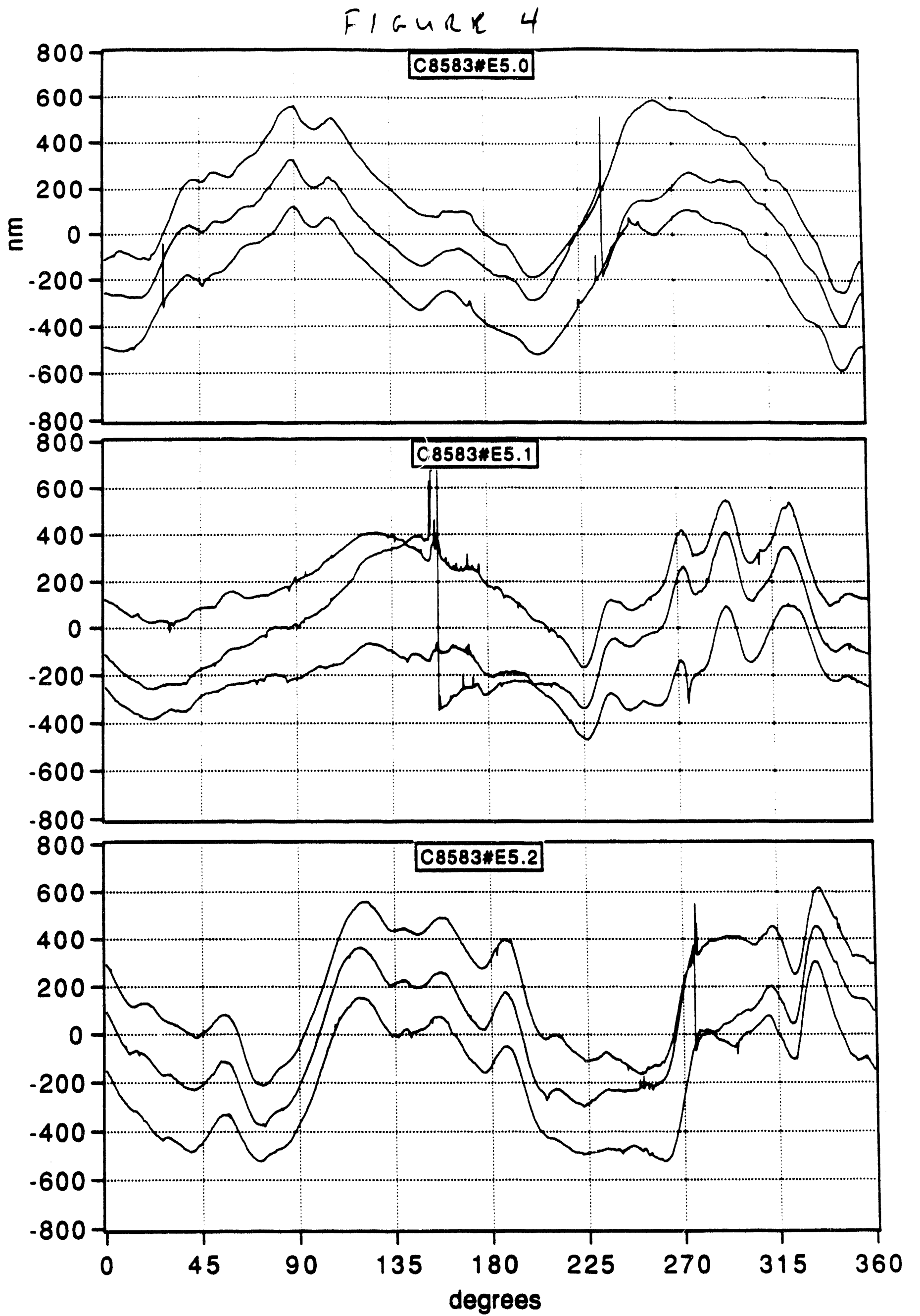




$$
\text { figure } 5
$$

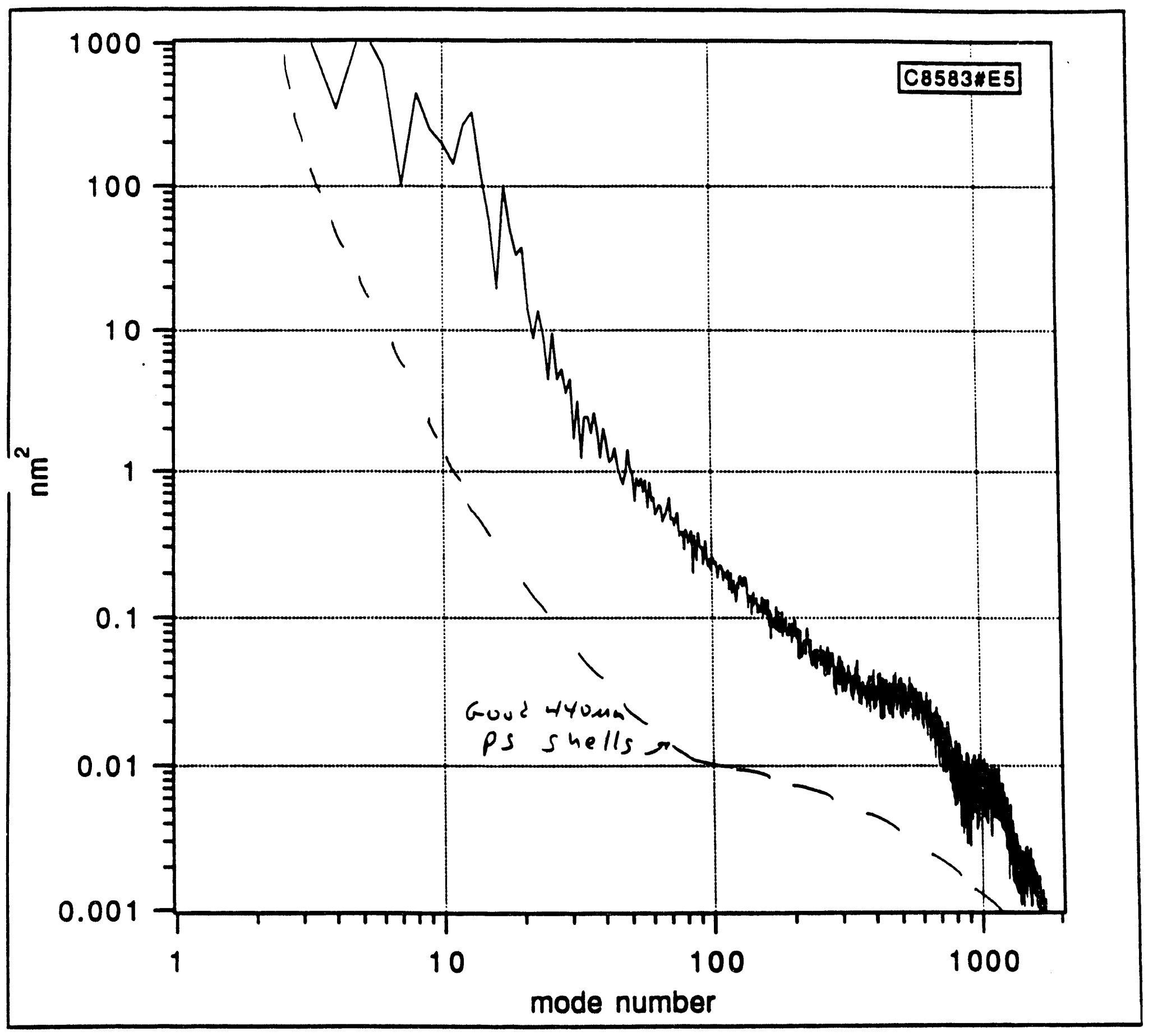




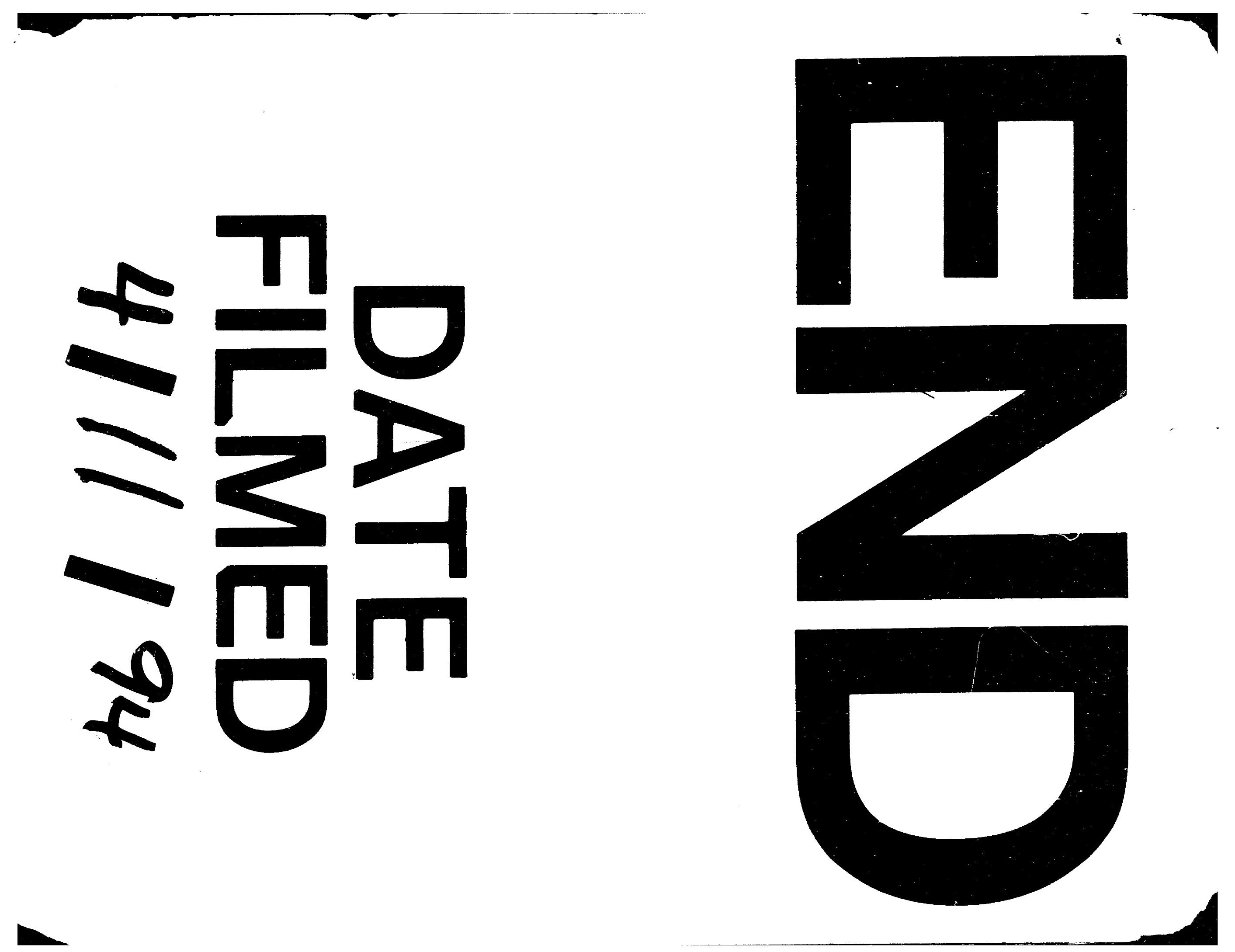

